\title{
The involvement of epoxygenase metabolites of arachidonic acid in cAMP-stimulated steroidogenesis and steroidogenic acute regulatory protein gene expression
}

\author{
XingJia Wang, Chwan-Li Shen ${ }^{3}$, Matthew T Dyson ${ }^{1}$, Xianling Yin², Randolph B Schiffer², Paula Grammas \\ and Douglas $\mathbf{M}$ Stocco ${ }^{1}$ \\ Departments of Neuropsychiatry, Garrison Institute on Aging, ${ }^{1}$ Cell Biology and Biochemistry, ${ }^{2}$ Neuropsychiatry, and ${ }^{3}$ Pathology, Texas Tech University Health \\ Sciences Center, Lubbock, Texas 79430, USA \\ (Requests for offprints should be addressed to X Wang; Email: xingjia.wang@ttuhsc.edu)
}

\begin{abstract}
The essential role of arachidonic acid (AA) in steroidogenesis has been previously demonstrated. The present study continues the investigation into how AA regulates steroidogenesis by examining the effects of epoxygenase-derived AA metabolites on cAMP-stimulated steroidogenic acute regulatory (StAR) gene expression and steroid hormone production in MA-10 mouse Leydig cells. The HPLC analysis of cell extracts from MA-10 cells treated with the cAMP analog dibutyryl cAMP (dbcAMP) demonstrated an increase in three epoxygenase-generated AA metabolites: 5,6-epoxyeicosatrienoic acid (EET), 8,9-EET, and 11,12-EET. Incubating MA-10 cells with each of the EETs induced a dosedependent increase in StAR protein expression and steroid

hormone production in the presence of dbcAMP. These metabolites also significantly enhanced StAR gene transcription as determined by luciferase assays of StAR promoter activity and reverse transcriptase-PCR analysis of StAR mRNA levels. While the EETs enhanced steroidogenesis, inhibiting the activity of protein kinase A (PKA) abolished the stimulatory effects of these AA metabolites on StAR expression and steroid hormone production. This study suggests that cAMP stimulation of MA-10 cells increases epoxygenase-generated AA metabolites and the co-action of these metabolites with PKA significantly increases StAR gene expression and steroid hormone production.

Journal of Endocrinology (2006) 190, 871-878
\end{abstract}

\section{Introduction}

The first committed enzymatic step in steroid hormone biosynthesis is the conversion of the substrate cholesterol to pregnenolone by the $\mathrm{P} 450$ side-chain cleavage enzyme (P450scc), which is located in the mitochondrial inner membrane. However, as a result of the aqueous barrier imposed by the mitochondrial intermembrane space, the transfer of cholesterol from the mitochondrial outer membrane to $\mathrm{P} 450 \mathrm{scc}$ becomes the true rate-limiting step during tropic hormone-stimulated steroidogenesis (Simpson \& Boyd 1966, 1967, Churchill \& Kimura 1979, Stocco \& Clark 1996). The steroidogenic acute regulatory (StAR) protein plays a critical function in this step by facilitating the delivery of cholesterol to the inner mitochondrial membrane (Clark et al. 1994, Lin et al. 1995, Wang et al. 1998, Stocco 2001). In testicular Leydig cells, StAR gene expression is primarily regulated by luteinizing hormone $(\mathrm{LH})$, but the mechanisms responsible for $\mathrm{LH}$ regulation of StAR gene expression are not completely clear. It is widely accepted that the LH stimulation of Leydig cells induces the formation of the second messenger cAMP, which activates protein kinase A (PKA), and leads to the phosphorylation of several transcription factors that regulate StAR gene transcription (Reinhart et al. 1999). Previous studies also indicated that $\mathrm{LH}$ and cAMP induce arachidonic acid (AA) release (Cooke et al. 1991, Moraga et al. 1997, Finkielstein et al. 1998, Ronco et al. 2002, Wang et al. 2002). After the release of AA, its metabolic derivatives transduce signals to the nucleus to regulate StAR gene expression and steroidogenesis (Cooke 1999, Wang \& Stocco 1999, Wang et al. 2000). We have previously demonstrated that both the PKA-phosphorylation pathway and the AA-mediated pathway are required for $\mathrm{LH}$-induced signal transduction that regulates StAR gene expression and steroid production, with neither pathway alone being sufficient for tropic hormone-stimulated steroidogenesis (Wang et al. 2000). These two signaling pathways serve in a concerted effort to regulate StAR gene expression and steroid hormone production, such that positive or negative changes in signaling from either pathway can dramatically affect StAR-mediated steroidogenesis (Wang \& Stocco 1999, Wang et al. 2000, 2002, 2003a).

In the AA-mediated signaling pathway, AA is mainly metabolized by one of the three groups of enzymes: 
the lipoxygenases, cyclooxygenases, or epoxygenases (Needleman et al. 1986). It was reported that AA metabolites specifically produced through the lipoxygenase pathway stimulated steroidogenesis (Dix et al. 1985, Nishikawa et al. 1994). Our previous studies indicated that cAMP stimulation of MA-10 mouse Leydig cells increased the synthesis of 5-lipoxygenase-generated metabolites of AA, namely, 5-hydroperoxyeicosatetraenoic acid (5-HPETE) and 5-hydroxyeicosatetraenoic acid (5-HETE), both of which enhanced cAMP-stimulated StAR expression (Wang et al. 2003b). Also, the inhibition of 5-lipoxygenase activity reduced StAR protein and steroidogenesis (Wang et al. 2000). In contrast to the action of 5-lipoxygenase in Leydig cells, the cyclooxygenase-2 enzyme (COX2, an isoform of cyclooxygenase) appears to be responsible for a tonic inhibition of StAR gene expression and steroid production (Wang et al. 2003a). The overexpression of COX2 in MA-10 cells reduced the steroidogenic sensitivity of the cells to cAMP stimulation. Similarly, the increased expression of COX2 in Leydig cells isolated from aging rats correlated with a reduction in StAR-mediated steroidogenesis (Wang et al. 2005). Presently, there is less evidence regarding what role the epoxygenases may serve with respect to StAR gene expression and steroid production. It was reported that LH or cAMP stimulation of granulosa cells increased 5,6-epoxyeicosatrienoic acid, an epoxygenase metabolite of AA, suggesting a possible role for this AA metabolite in granulosa cell steroidogenesis (Zosmer et al. 1990, 2002). In addition, we have previously reported that inhibiting epoxygenase activity reduced StAR protein expression and steroid production in MA-10 mouse Leydig cells (Wang et al. 2000). In order to completely understand how the signaling pathways involving AA metabolism are implicated in the regulation of steroidogenesis, we have analyzed the production of epoxygenase-derived AA metabolites in MA-10 cells following stimulation with a cAMP analog. Then, we examined the effects of these metabolites on StAR gene expression and steroidogenesis. Our findings indicate that the cAMP stimulation of MA-10 cells results in the increase of several AA metabolites produced by epoxygenase activity that are each capable of significantly enhancing cAMP-stimulated StAR gene expression and steroid hormone production.

\section{Materials and Methods}

\section{Reagents}

$\mathrm{N}^{6}, 2$-Dibutyryladenosine 3:5-cyclic monophosphate (dbcAMP) was purchased from Sigma. ( \pm )5(6)-epoxy-8Z, 11Z,14Z-eicosatrienoic acid (5,6-EET), ( \pm )8(9)-epoxy-5Z, 11Z,14Z-eicosatrienoic acid (8,9-EET), ( \pm ) 11(12)-epoxy-5Z, 8Z,14Z-eicosatrienoic acid (11,12-EET), ( \pm )14(15)-epoxy-5Z,8Z,11Z-eicosatrienoic acid (14,15-EET), 5(S)-hydro$\mathrm{xy}-6 \mathrm{E}, 8 \mathrm{Z}, 11 \mathrm{Z}, 14 \mathrm{Z}$-eicosatetraenoic acid (5-HETE), and 5(S)-hydroperoxy-6E,8Z,11Z, 14Z-eicosatetraenoic acid
(5-HPETE) were purchased from Cayman (Ann Arbor, MI, USA). Rabbit antiserum generated against StAR protein was a generous gift from Prof W L Miller (Department of Pediatrics and the Metabolic Research Unit, University of California San Francisco, San Francisco, CA, USA; Bose et al. 1999). Donkey anti-rabbit IgG antibody conjugated with horseradish peroxidase was purchased from Biosource (Camarillo, CA, USA). Waymouth's MB/752 medium was obtained from Sigma. Horse serum was purchased from Invitrogen. The Dual-Luciferase Reporter Assay System was purchased from Promega. The other common chemicals used in this study were obtained from either Sigma or Fisher Chemicals (Pittsburgh, PA, USA).

\section{Cell culture}

The MA-10 mouse Leydig tumor cell line was a generous gift from Dr Mario Ascoli (Department of Pharmacology, University of Iowa, College of Medicine, Iowa City, IA, USA) and were cultured in 12-well culture plates in Waymouth's $\mathrm{MB} / 752$ medium containing $15 \%$ horse serum as previously described (Ascoli 1981). The cells were cultured in an incubator at $37^{\circ} \mathrm{C}$ and $5 \% \mathrm{CO}_{2}$. Before each experiment, the medium was replaced with serum-free Waymouth's medium.

\section{HPLC analysis of arachidonic acid metabolites}

The methods previously described were modified for extraction and HPLC separation of AA metabolites (Powell 1982, Borgeat et al. 1990). MA-10 cells in $100 \mathrm{~mm}$ culture plates were incubated in $5 \mathrm{ml}$ Waymouth's medium containing $1.5 \%$ horse serum and $25 \mu \mathrm{Ci} / \mathrm{ml}^{3} \mathrm{H}$-AA for $4 \mathrm{~h}$. The cells were washed twice with $5 \mathrm{ml}$ Waymouth's medium containing $0 \cdot 1 \%$ fatty acid-free BSA. The cells were then incubated in $5 \mathrm{ml}$ Waymouth's medium and stimulated with $1.0 \mathrm{mM}$ dbcAMP for $6 \mathrm{~h}$. The stimulation was terminated by their transfer to $-80{ }^{\circ} \mathrm{C}$ and the addition of $1.0 \mathrm{ml}$ cold methanol containing $5 \mu \mathrm{l}$ of $37 \% \mathrm{HCl}$ and $15 \mu \mathrm{g}$ non-labeled standards, including AA and a mixture of several AA metabolites $(3 \mu \mathrm{g}$ of each: 5,6-EET, 8,9-EET, 11,12-EET, 14,15-EET, 5-HETE, and 5-HPETE). The cells were collected and centrifuged at $8000 \mathrm{~g}$ for $20 \mathrm{~min}$. The resulting supernatants were loaded onto $3 \mathrm{ml} / 500 \mathrm{mg}$ Discovery DSC-18 SPE tubes (Supelco, Bellefonte, PA, USA) preconditioned with washes of $3 \mathrm{ml}$ methanol followed by $3 \mathrm{ml}$ water. The tubes were then eluted with $3 \mathrm{ml}$ methanol, followed by $3 \mathrm{ml}$ acetonitrile. The elutes from the tubes were dried under nitrogen and resuspended in $350 \mu \mathrm{l}$ of $60 \%$ acetonitrile. The concentrated extracts were immediately analyzed by RP-HPLC with a Gradient Component System consisting of two 515 HPLC pumps (Waters, Milford, MA, USA) on a Discovery C18 column $(4.6 \mathrm{~mm} \times 25 \mathrm{~cm}, 5 \mu \mathrm{m}$ particle size; Supelco), and using a stepped gradient of solvent A, containing water/acetonitrile/ methanol/phosphoric acid $(75 / 12 \cdot 5 / 12 \cdot 5 / 0 \cdot 01)$, and solvent $\mathrm{B}$, containing water/acetonitrile/methanol/phosphoric acid $(5 / 63 / 32 / 0 \cdot 01)$. The gradient steps used are as follows: $0 \mathrm{~min}$, 
$100 \% \mathrm{~A}, 1 \cdot 0 \mathrm{ml} / \mathrm{min}$; $0-10 \mathrm{~min}, 44 \% \mathrm{~A}+56 \% \mathrm{~B}, 0 \cdot 98 \mathrm{ml} / \mathrm{min}$; $10-89 \mathrm{~min}, \quad 40 \% \mathrm{~A}+60 \% \mathrm{~B}, \quad 0.96 \mathrm{ml} / \mathrm{min} ; \quad 89-140 \mathrm{~min}$, $100 \% \mathrm{~B}, 0.96 \mathrm{ml} / \mathrm{min}$. The sample was analyzed spectrophotometrically at 206 and $235 \mathrm{~nm}$ using a Waters 2487 Dual $\lambda$ Absorbance Detector (Waters). The column elute was directly collected into scintillation vials and the radioactivities of the fractions were measured using a Beckman LS 6500 scintillation counter (Beckman, Fullerton, CA, USA).

\section{Steroid production}

MA-10 cells were cultured for $30 \mathrm{~min}$ in serum-free Waymouth's medium containing 5,6-EET, 8,9-EET, or 11,12-EET respectively (as described in Figures) and $0.2 \mathrm{mM}$ dbcAMP was added to the culture for $6 \mathrm{~h}$. The medium was collected at the end of each experiment and stored at $-80{ }^{\circ} \mathrm{C}$. Progesterone concentrations in the medium were determined by RIA (Resko et al. 1974).

\section{Western blot analysis}

StAR protein in MA-10 cells was detected by Western blot analysis as described previously (Townson et al. 1996). Western blot analysis experiments were performed at least three times and the results of one representative experiment are shown in the Figures.

\section{Transfection}

MA-10 cells were cultured in 12 -well plates $(0 \cdot 2 \times$ $10^{6}$ cells/well) overnight. The cells in each well were transfected with $0.5 \mu \mathrm{g}$ DNA of the StAR promoter/luciferase plasmid PGL2/StAR expressing firefly luciferase driven by the - 966 bp sequence of the StAR promoter (Caron et al. 1997). Transfections also included $6 \cdot 0 \mathrm{ng} \mathrm{pRL}-\mathrm{SV} 40$ vector DNA (a plasmid, which constitutively expresses Renilla luciferase under the control of the SV40 promoter; Promega). Transfections were performed using FuGENE6 Transfection reagent (Roche) following the manufacturer's instructions. After 48-h culture, the cells were utilized for further experiments.

\section{Luciferase assays}

Following experiments, the cells were washed thrice with ice-cold PBS and lysed with Passive Lysis Buffer (Promega). The supernatants were utilized for luciferase assays using a Dual Luciferase Reporter Assay System following the manufacturer's instructions (Promega). The relative light units (determined by dividing the reading from the PGL2/StAR promoter by the reading from Renilla luciferase) were measured using a TD20/20 luminometer (Turner Designers, Sunnyvale, CA, USA).

\section{Reverse transcriptase (RT)-PCR}

In experiments designed to determine StAR mRNA expression, cells were washed thrice with cold PBS and used for total RNA purification using TRIzol reagent in accordance with the manufacturer's instructions (Invitrogen). RT-PCR was performed as previously described (Rao et al. 2003). A ribosomal protein L19 was used as internal Marker in the RT-PCR (Al-Bader \& Al-Sarraf 2005).

\section{Statistical analysis}

Each experiment was repeated at least three times. Statistical analysis of the data was performed with ANOVA and Fisher's protected least significant difference test using the Stat View SE system (Abacus Concepts, Berkeley, CA, USA). The data are shown as the mean \pm s.E.M.

\section{Results}

HPLC analysis of CAMP-induced epoxygenase metabolites of arachidonic acid

To determine how the profile of epoxygenase-derived AA metabolites changes in response to cAMP, MA-10 Leydig cells loaded with ${ }^{3} \mathrm{H}-\mathrm{AA}$ were incubated with or without the cAMP analog dbcAMP and the AA metabolites from these cells were resolved by HPLC. Our results indicated that MA-10 cells stimulated with dbcAMP have increased amounts of three epoxygenase-derived AA metabolites: 5,6-EET, 8,9-EET, and 11,12-EET. Total detected amounts of 8,9-EET and 11,12EET were significantly increased by $120 \%$ and $81 \%$, respectively, over the levels seen in controls $(P<0 \cdot 05)$. The amount of 5,6-EETwas also increased by dbcAMP stimulation, but the increase is not statistically significant (Fig. 1).

\section{EET-enhanced StAR protein expression and steroid hormone production}

Since EET concentrations appeared to increase in MA-10 cells following treatment with dbcAMP, we sought to determine whether EETs served in a causative role in regulating StAR expression and steroidogenesis. MA-10 cells were incubated with increasing concentrations of 5,6-EET, 8,9-EET, or 11,12EET in medium containing $0.2 \mathrm{mM}$ dbcAMP. Figures 2-4 show the steroid hormone production and StAR protein expression that followed each of these dose-response treatments. Treating MA- 10 cells with $0 \cdot 2 \mathrm{mM}$ dbcAMP alone consistently resulted in a small detectable rise in steroidogenesis. Since EET concentrations in the medium increased from 0 to $20 \mu \mathrm{M}$, StAR protein increased in a dose-dependent manner. Concomitant with the increase in StAR protein, steroid hormone production also increased significantly compared with that of cells treated with $0.2 \mathrm{mM}$ dbcAMP alone. To ascertain whether the increases in steroid hormone production resulted from increased activity of P450scc itself, the levels of $\mathrm{P} 450 \mathrm{scc}$ protein were analyzed by Western blot and 22(R)hydroxycholesterol, a membrane-permeable form of cholesterol, was also included during the stimulation. Incubation of the cells with the EETs did 

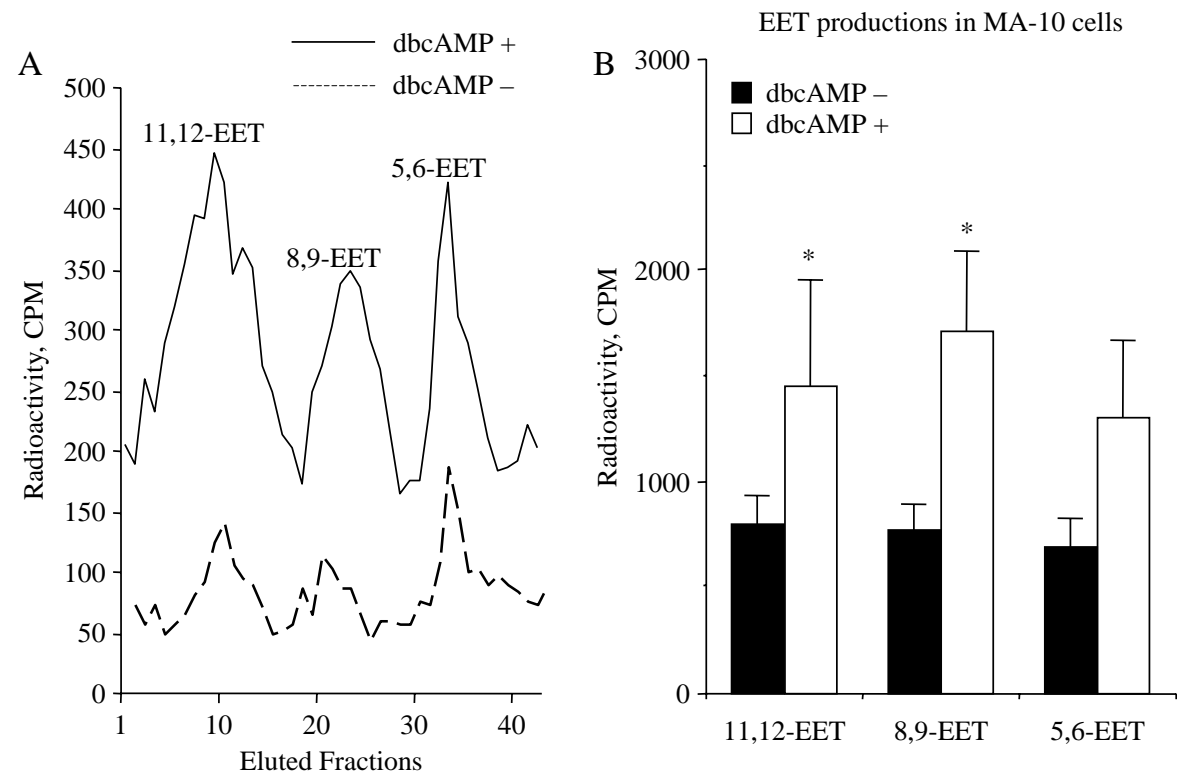

Figure 1 Stimulation with dbcAMP increased epoxygenase-generated AA metabolites in MA-10 mouse Leydig cells. MA-10 cells pre-loaded with ${ }^{3} \mathrm{H}$-AA were stimulated with $1.0 \mathrm{mM}$ dbcAMP for $6 \mathrm{~h}$. AA metabolites were then extracted and separated by HPLC. The column elute was collected directly into scintillation vials and the radioactivities of the fractions were measured using a Beckman LS 6500 scintillation counter (Beckman). (A) A representative chromatogram of HPLC for EET separation. (B) The averages of the total radioactivity for the samples in the peak areas of 5,6EET, 8,9-EET, and 11,12-EET from five individual experiments. *Significantly different compared with the cells without dbcAMP stimulation $(P<0 \cdot 05)$.

not induce an obvious increase in the levels of the P450scc protein. There was no significant difference in steroid production among the treatments when the cells were cultured with 22(R)hydroxycholesterol for 6 h (Fig. 5).

\section{EET-enhanced StAR gene transcription}

To understand how these epoxygenated AA metabolites might serve to enhance StAR protein expression, we investigated the effects that the EETs had on StAR gene transcription in the presence of $0.2 \mathrm{mM}$ dbcAMP. The relative abundance of StAR mRNA levels in the EET-treated MA-10 cells was determined by RT-PCR, and the activity of the StAR promoter under the same conditions was analyzed by luciferase assay. The results in Fig. 6 show that each EET tested increased StAR mRNA levels in MA-10 Leydig cells relative to $0.2 \mathrm{mM}$ dbcAMP. These increases were paralleled by increases in StAR promoter activity. In the cells treated with $20 \mu \mathrm{M}$ of 5,6-EET, 8,9-EET, or 11,12EET, StAR promoter activities increased by $3 \cdot 0-, 2 \cdot 6-$, and $3 \cdot 8$-fold, respectively, over the level of the cells treated with $0 \cdot 2 \mathrm{mM}$ dbcAMP alone.

\section{Essential roles of $C A M P$ and PKA activity in EET-enhanced steroidogenesis}

Each of the EETs was added to MA-10 cell cultures with or without $0.2 \mathrm{mM}$ dbcAMP to determine the role of this low level of cAMP analog in EET-enhanced StAR gene expression and steroid hormone production. As shown in Fig. 7 , in the absence of dbcAMP, none of the EETs alone were able to induce a significant increase in steroidogenesis, whereas in the presence of $0.2 \mathrm{mM}$ dbcAMP, all of them dramatically increased StAR protein and steroid hormone production to the levels of maximal stimulation. Also, the inhibition of PKA activity using the selective inhibitor, H89, abolished the stimulatory effects of the EETs on StAR protein expression and steroid hormone production (Fig. 8).

\section{Discussion}

Previous studies have demonstrated the essential role of AA-mediated signal transduction in steroid hormone production (Abayasekara et al. 1990, Maloberti et al. 2000, Castilla et al. 2004, Cornejo Maciel et al. 2005) and StAR gene expression (Wang \& Stocco 1999, Wang et al. 1999, 2000, 2005); however, much remains unknown regarding the manner in which AA transduces its signals to the nucleus after its release in response to $\mathrm{LH}$ receptor activation. Since AA is usually metabolized along one of the three different enzymatic pathways: the lipoxygenase, cyclooxygenase, and epoxygenase (Needleman et al. 1986), we attempted to further characterize how these metabolic pathways are involved in the signal transduction controlling StAR gene expression and steroid hormone production. Following our previous studies 
A

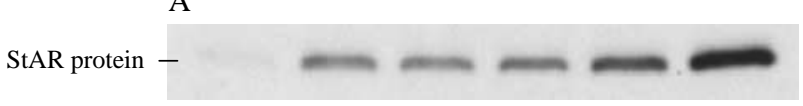

B
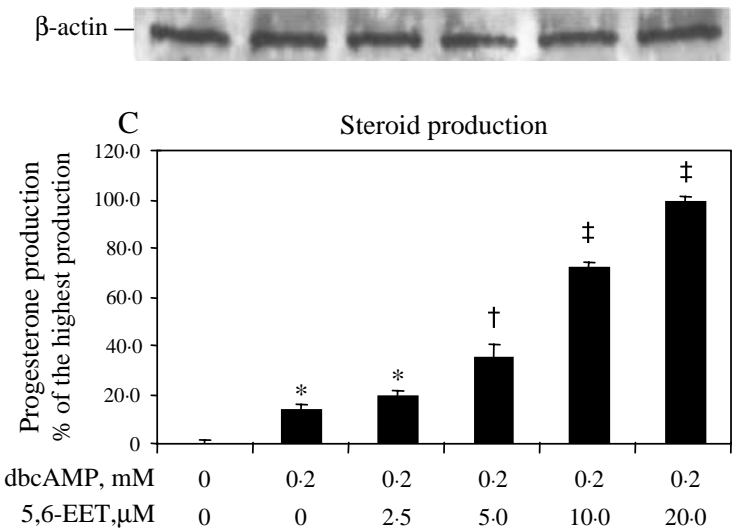

Figure 2 5,6-EET-enhanced StAR protein expression and steroid hormone production in MA-10 mouse Leydig cells. MA-10 cells were pre-incubated with increasing levels of 5,6-EET for $30 \mathrm{~min}$ and $0.2 \mathrm{mM}$ dbcAMP was added to the cell culture. After $6 \mathrm{~h}$, samples of the cells and culture medium were collected and stored at $-80^{\circ} \mathrm{C}$. (A) StAR protein and (B) $\beta$-actin in the cells were detected by Western blot analysis and $(\mathrm{C})$ progesterone concentrations in the medium were determined by RIA. *Significantly different from control $(P<0 \cdot 05)$. ${ }^{+}$Highly significantly different from control $(P<0 \cdot 01) .{ }^{\ddagger}$ Very highly significantly different from control $(P<0 \cdot 001)$.

that focused on the roles of lipoxygenase and cyclooxygenase in steroidogenesis (Wang et al. 2003a,2003b, 2005), the present study demonstrates that the epoxygenases also play a role in CAMP-induced StAR gene expression and steroid hormone biosynthesis in MA-10 mouse Leydig cells.

The involvement of epoxygenase metabolites of AA in cAMP-stimulated steroidogenesis is supported by the results from HPLC analysis of the AA metabolites extracted from MA-10 cells stimulated with dbcAMP. Stimulation with this cAMP analog not only increased AA release, as reported previously (Maloberti et al. 2000, Wang et al. 2002, Castilla et al. 2004), but also appeared to enhance AA metabolism through the epoxygenase pathway and resulted in increases in its metabolites 5,6-EET, 8,9-EET, and 11,12-EET. All of these AA metabolites significantly stimulated steroid hormone production in MA-10 Leydig cells. These stimulatory effects can readily be seen from the concentration-dependent increases in progesterone production in MA-10 cells incubated with increasing levels of these metabolites. A similar observation was reported previously in human granulosa cells (Zosmer et al. 1990, 2002). The results from the present and previous studies suggest that LH or cAMP stimulation enhance the positive steroidogenic signals produced through the AA signaling pathway by increasing the levels of epoxygenase-generated AA metabolites, which in turn enhance steroid hormone production.

The mechanism by which the epoxygenase metabolites of AA enhance steroid hormone production is unknown. The

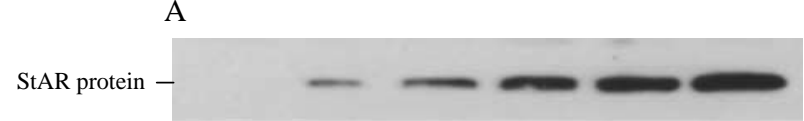

B
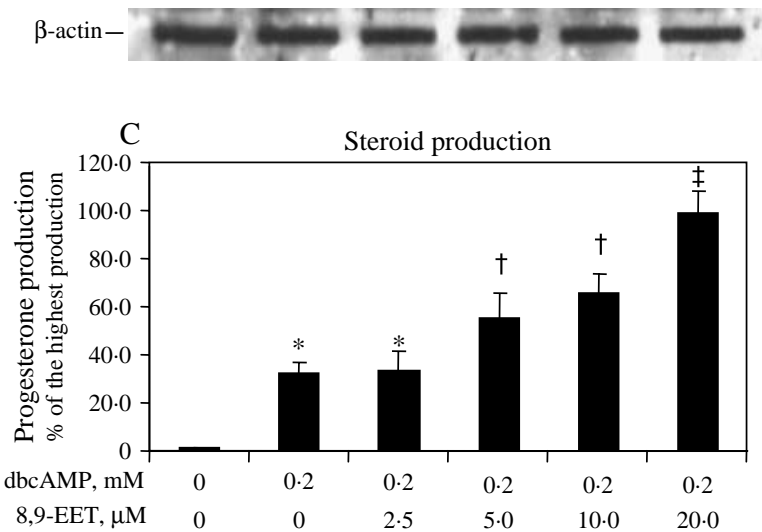

Figure 3 8,9-EET-enhanced StAR protein expression and steroid hormone production in MA-10 mouse Leydig cells. MA-10 cells were pre-incubated with increasing levels of 8,9-EET for $30 \mathrm{~min}$ and $0 \cdot 2 \mathrm{mM}$ dbcAMP was added to the cell culture. After $6 \mathrm{~h}$ samples of the cells and culture medium were collected and stored at $-80^{\circ} \mathrm{C}$. (A) StAR protein and (B) $\beta$-actin in the cells were detected by Western blot analysis and $(C)$ progesterone concentrations in the medium were determined by RIA. *Significantly different from control $(P<0 \cdot 05)$. ${ }^{+}$Highly significantly different from control $(P<0 \cdot 01)$. ${ }^{\ddagger}$ Very highly significantly different from control $(P<0 \cdot 001)$.

results from the experiments with 22(R)-hydroxycholesteroltreated MA-10 cells suggest that the increase in steroid hormone production is mainly due to the increased supply of the substrate to the inner mitochondrial membrane, since there was no significant difference in steroid hormone production among the treatments when this substrate was used. This observation encouraged us to analyze StAR protein in the cells, a protein critical for cholesterol transfer from the outer to inner mitochondrial membrane. The results from Western blot analyses indicated that each of these epoxygenase-generated AA metabolites increased StAR protein expression. The increases in StAR protein expression occurred concomitantly with the increases in progesterone production in EET-treated MA-10 cells. This is in keeping with our earlier observations that the inhibition of epoxygenase activity in MA-10 cells reduced StAR protein expression and steroidogenesis (Wang et al. 2000). While other steroidogenic factors might be involved in EETincreased steroidogenesis, these observations suggest that the epoxygenase-generated AA metabolites enhanced steroid hormone production mainly through its regulation of StAR protein expression.

The present study further suggests that the AA metabolites produced by epoxygenase activity regulate StAR gene expression at the level of transcription. This was supported by the results from luciferase assays of StAR promoter activities and RT-PCR analysis of StAR mRNA levels. The mechanisms by 


\section{A}

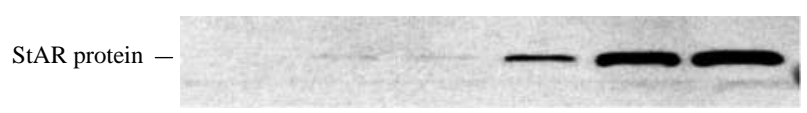

B
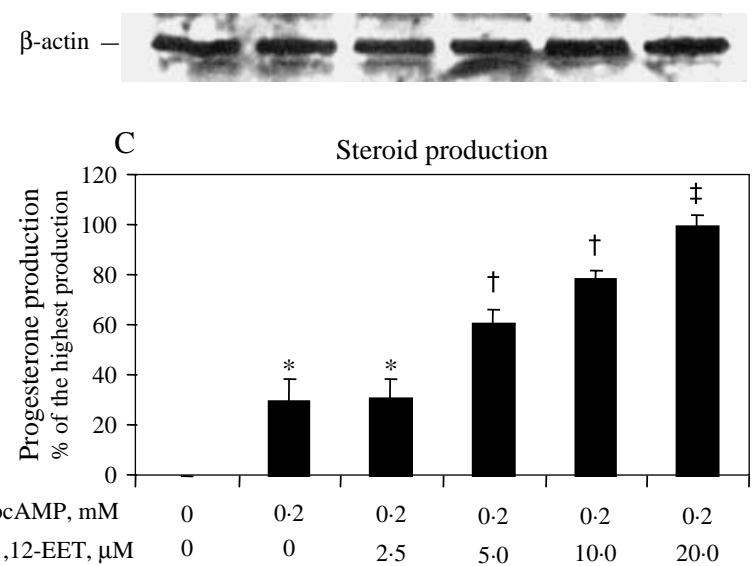

Figure 4 11,12-EET-enhanced StAR protein expression and steroid hormone production in MA-10 mouse Leydig cells. MA-10 cells were pre-incubated with increasing levels of 11,12-EET for $30 \mathrm{~min}$ and $0 \cdot 2 \mathrm{mM}$ dbcAMP was added to the cell culture. After $6 \mathrm{~h}$ samples of the cells and culture medium were collected and stored at $-80^{\circ} \mathrm{C}$. (A) StAR protein and (B) $\beta$-actin in the cells were detected by Western blot analysis and $(C)$ progesterone concentrations in the medium were determined by RIA. *Significantly different from control $(P<0 \cdot 05)$. ${ }^{\dagger}$ Highly significantly different from control $(P<0 \cdot 01) .{ }^{\ddagger}$ Very highly significantly different from control $(P<0 \cdot 001)$.
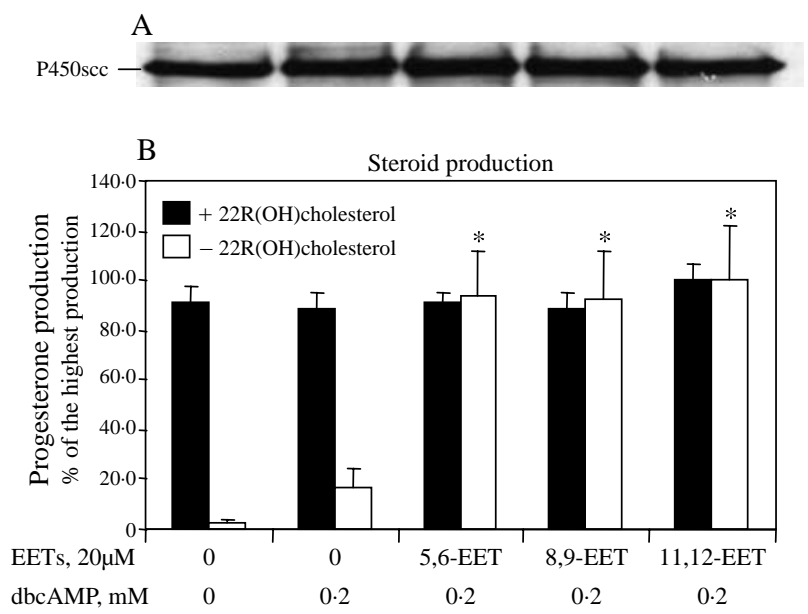

Figure 5 Steroid hormone production in EET-treated MA-10 cells using (22)hydroxycholesterol as substrate. MA-10 cells were preincubated with $20 \mu \mathrm{M} \mathrm{5,6-EET,} \mathrm{8,9-EET,} \mathrm{or} \mathrm{11,12-EET,} \mathrm{respectively,}$ for $30 \mathrm{~min}$ in a medium with or without $25 \mu \mathrm{M}$ (22)hydroxycholesterol. Then $0 \cdot 2 \mathrm{mM}$ dbcAMP was added to cell cultures for $6 \mathrm{~h}$. Samples of the cells and culture medium were collected and stored at $-80^{\circ} \mathrm{C}$. (A) P450scc was detected by Western blot analysis and (B) Progesterone concentrations in the medium were determined by RIA. *Highly significantly different from control $(P<0 \cdot 01)$.
A

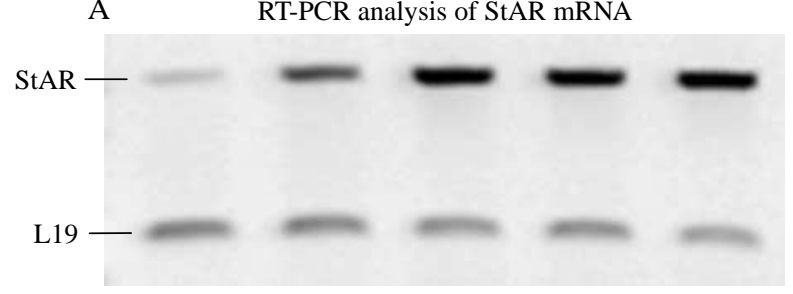

B

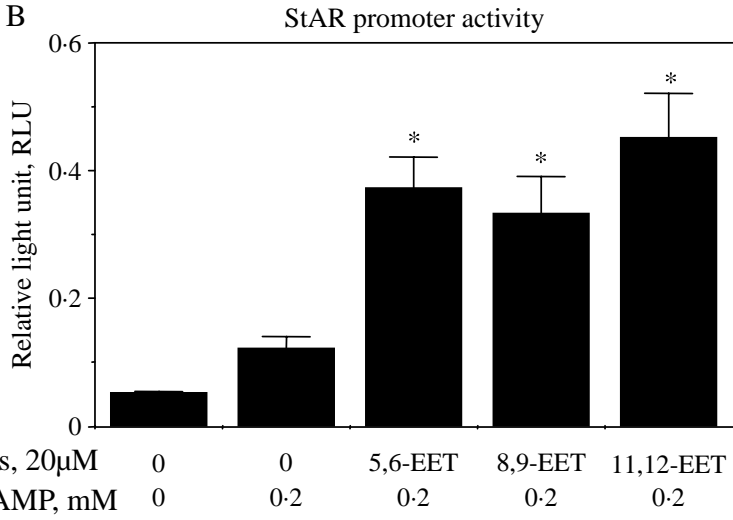

Figure 6 EET-enhanced StAR gene transcription in MA-10 mouse Leydig cells. MA-10 cells were pre-incubated with $20 \mu \mathrm{M}$ of 5,6EET, 8,9-EET, or 11,12-EET, respectively for $30 \mathrm{~min}$. Then the cells were treated with or without $0 \cdot 2 \mathrm{mM}$ dbcAMP for $6 \mathrm{~h}$. (A) Total RNA in the cells were isolated using TRIzol reagent following the manufacturer's instructions. StAR mRNA levels in the cells were analyzed by RT-PCR. (B) For StAR promoter activity, MA-10 cells were transfected with the PGL2/-966StAR promoter/luciferase plasmid. Transfections also included the pRL-SV40 vector DNA (a plasmid which constitutively expresses Renilla luciferase, a control reporter under the control of the SV40 promoter). After 48-h culture, the cells were treated as described earlier, then washed and lysed with Passive Lysis Buffer (Promega). The supernatants were utilized for luciferase assays using a Dual Luciferase Reporter Assay System. StAR promoter activities were expressed as relative light units (RLU). *Highly significantly different compared with cells stimulated with $0 \cdot 2 \mathrm{mM}$ dbcAMP alone $(P<0 \cdot 01)$.

which EETs influence StAR promoter activity are unknown and thus could act directly or indirectly to effect changes in promoter activity. It will be interesting to determine whether the EETs induce or activate specific transcription factors that bind to the StAR promoter and enhance StAR gene transcription.

Whereas increases in EETs were capable of enhancing StAR gene expression in the presence of cAMP, none of them alone was able to increase StAR promoter activity, StAR mRNA level, and StAR protein or steroid hormone production. Also, the inhibition of PKA activities with the selective PKA inhibitor H89 significantly reduced the EET-increased StAR protein expression and steroid hormone production. These results suggested that signaling through the cAMP-PKA-phosphorylation pathway is necessary for the EETs to elicit their steroidogenic response. This observation is consistent with results from our previous studies (Wang et al. 


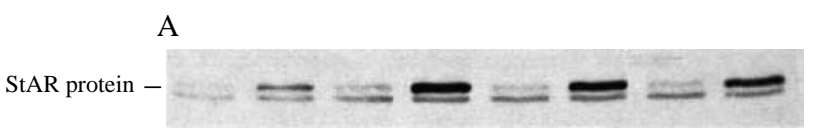

B
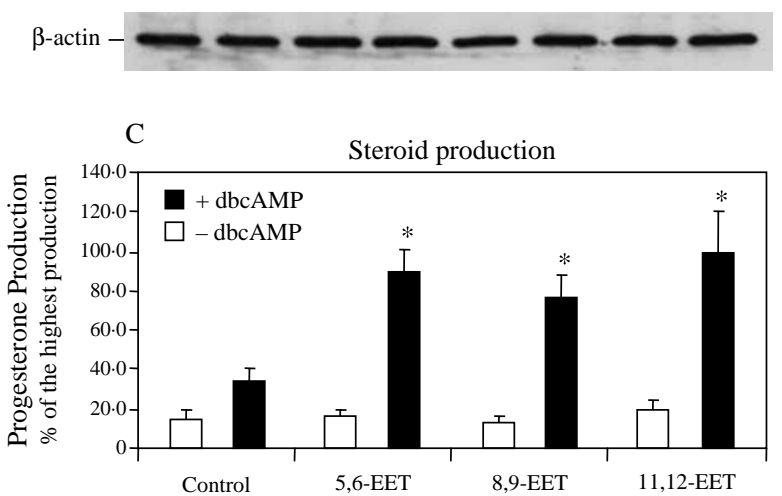

Figure 7 EET-enhanced StAR protein expression and steroid hormone production in MA-10 cells treated with or without dbcAMP. MA-10 cells were pre-incubated with $20 \mu \mathrm{M}$ of 5,6-EET, $8,9-\mathrm{EET}$, or $11,12-\mathrm{EET}$, respectively for $30 \mathrm{~min}$. Then the cells were treated with or without $0.2 \mathrm{mM}$ dbcAMP. After $6 \mathrm{~h}$, samples of the cells and culture medium were collected and stored at $-80^{\circ} \mathrm{C}$. (A) StAR protein and (B) $\beta$-actin in the cells were detected by Western blot analysis and $(C)$ progesterone concentrations in the medium were determined by RIA. *Highly significantly different from control $(P<0 \cdot 01)$.
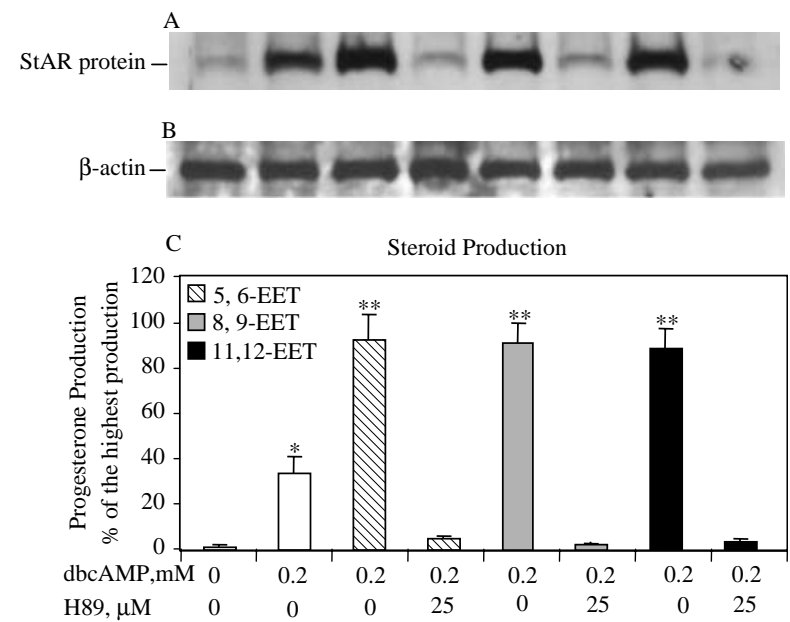

Figure 8 Inhibitory effect of a PKA inhibitor on EET-enhanced StAR protein expression and steroid hormone production in MA-10 cells. MA-10 cells were pre-treated with $25 \mu \mathrm{M}$ of the PKA inhibitor H89 in a culture medium containing $20 \mu \mathrm{M}$ of 5,6-EET, 8,9-EET, or 11,12 -EET, respectively for $30 \mathrm{~min}$. Then the cells were treated with $0.2 \mathrm{mM}$ dbcAMP. After $6 \mathrm{~h}$, samples of the cells and culture medium were collected and stored at $-80^{\circ} \mathrm{C}$. (A) StAR protein and (B) $\beta$-actin in the cells were detected by Western blot analysis and (C) progesterone concentrations in the medium were determined by RIA. *Significantly different from control $(P<0 \cdot 05)$. **Highly significantly different from control $(P<0 \cdot 01)$.
2000). In those studies, we determined that without PKAphosphorylation, AA-mediated signaling alone is unable to induce StAR gene expression and steroidogenesis. On the other hand, if AA-release or its metabolism by epoxygenase and lipoxygenase is blocked by the use of specific inhibitors, even high levels of cAMP or PKA-phosphorylation could not stimulate significant increases in StAR gene expression and steroid hormone production (Wang et al. 2000). These data support the concept that in LH or cAMP-stimulated steroidogenesis, signal transduction through both the cAMP-PKA-phosphorylation pathway and the AA pathway are required to accomplish maximal steroidogenesis in response to tropic hormone stimulation.

From the results of the present and previous studies (Wang \& Stocco 1999, Wang et al. 2002, 2003a,2003b), it can readily be seen that in the AA-mediated signaling pathway, both positive and negative signals are produced to regulate StAR gene expression. The positive signals are generated by 5-lipoxygenase activity that converts AA to 5-HPETE and 5-HETE as reported previously (Wang et al. 2003b) and also by epoxygenase activity that converts AA to various EETs as discussed earlier. These AA metabolites act together to stimulate StAR gene expression when minimal levels of PKA-mediated phosphorylating activity are present in the cells. The negative signals were produced through the activity of COX2. Although the mechanism for the action of COX2 has not been elucidated completely, its expression resulted in inhibitory effects on StAR gene expression and steroidogenesis in Leydig cells (Wang et al. 2005). Therefore, the levels of these three enzymes in Leydig cells regulate the intracellular levels and the ratios of the positive and negative signals, which in turn may serve to regulate the sensitivity of Leydig cells to LH or cAMP stimulation.

\section{Acknowledgements}

The authors would like to acknowledge the support of NIH Grant AG025349 and AOA grant from the Institute for Healthy Aging, TTUHSC to X J W, the support of NIH grant HD17481 and funds from the Robert A Welch Foundation grant B1-0028 to D M S and support of NIH Grants AG15964 and AG020569 to P G. The authors declare that there is no conflict of interest that would prejudice the impartiality of this scientific work.

\section{References}

Abayasekara DR, Band AM \& Cooke BA 1990 Evidence for the involvement of phospholipase A2 in the regulation of luteinizing hormone-stimulated steroidogenesis in rat testis Leydig cells. Molecular and Cellular Endocrinology 70 147-153.

Al-Bader MD \& Al-Sarraf HA 2005 Housekeeping gene expression during fetal brain development in the rat-validation by semi-quantitative RT-PCR. Brain Research. Developmental Brain Research 156 38-45. 
Ascoli M 1981 Characterization of several clonal lines of cultured Leydig tumor cells: gonadotropin receptors and steroidogenic responses. Endocrinology 108 88-95

Borgeat P, Picard S, Vallerand P, Bourgoin S, Odeimat A, Sirois P \& Poubelle PE 1990 Automated on-line extraction and profiling of lipoxygenase products of arachidonic acid by high-performance liquid chromatography. Methods in Enzymology 187 98-116.

Bose HS, Whittal RM, Baldwin MA \& Miller WL 1999 The active form of the steroidogenic acute regulatory protein, StAR, appears to be a molten globule. PNAS 96 7250-7255.

Caron KM, Ikeda Y, Soo SC, Stocco DM, Parker KL \& Clark BJ 1997 Characterization of the promoter region of the mouse gene encoding the steroidogenic acute regulatory protein. Molecular Endocrinology 11 138-147.

Castilla R, Maloberti P, Castillo F, Duarte A, Cano F, Maciel FC, Neuman I, Mendez CF, Paz C \& Podesta EJ 2004 Arachidonic acid regulation of steroid synthesis: new partners in the signaling pathway of steroidogenic hormones. Endocrine Research 30 599-606.

Churchill PF \& Kimura T 1979 Topological studies of cytochromes P-450scc and P-45011 beta in bovine adrenocortical inner mitochondrial membranes. Effects of controlled tryptic digestion. Journal of Biological Chemistry 254 10443-10448.

Clark BJ, Wells J, King SR \& Stocco DM 1994 The purification, cloning, and expression of a novel luteinizing hormone-induced mitochondrial protein in MA-10 mouse Leydig tumor cells. Characterization of the steroidogenic acute regulatory protein (StAR). Journal of Biological Chemistry $26928314-28322$.

Cooke BA 1999 Signal transduction involving cyclic AMP-dependent and cyclic AMP-independent mechanisms in the control of steroidogenesis. Molecular and Cellular Endocrinology $15125-35$.

Cooke BA, Dirami G, Chaudry L, Choi MS, Abayasekara DR \& Phipp L 1991 Release of arachidonic acid and the effects of corticosteroids on steroidogenesis in rat testis Leydig cells. Journal of Steroid Biochemistry and Molecular Biology 40 465-471.

Cornejo Maciel F, Maloberti P, Neuman I, Cano F, Castilla R, Castillo F, Paz C \& Podesta EJ 2005 An arachidonic acid-preferring acyl-CoA synthetase is a hormone-dependent and obligatory protein in the signal transduction pathway of steroidogenic hormones. Journal of Molecular Endocrinology 34 655666.

Dix CJ, Habberfield AD, Sullivan MH \& Cooke BA 1985 Evidence for the involvement of lipoxygenase products in steroidogenesis. Biochemical Society Transactions 13 60-63.

Finkielstein C, Maloberti P, Mendez CF, Paz C, Cornejo Maciel F, Cymeryng C, Neuman I, Dada L, Mele PG, Solano A et al. 1998 An adrenocorticotropinregulated phosphoprotein intermediary in steroid synthesis is similar to an acyl-CoA thioesterase enzyme. European Journal of Biochemistry 256 60-66.

Lin D, Sugawara T, Strauss JF III, Clark BJ, Stocco DM, Saenger P, Rogol A \& Miller WL 1995 Role of steroidogenic acute regulatory protein in adrenal and gonadal steroidogenesis. Science 267 1828-1831.

Maloberti P, Mele PG, Neuman I, Cornejo Maciel F, Cano F, Bey P, Paz C \& Podesta EJ 2000 Regulation of arachidonic acid release in steroidogenesis: role of a new acyl-CoA thioestrase (ARTISt). Endocrine Research $\mathbf{2 6}$ 653-662.

Moraga PF, Llanos MN \& Ronco AM 1997 Arachidonic acid release from rat Leydig cells depends on the presence of luteinizing hormone/human chorionic gonadotrophin receptors. Journal of Endocrinology 154 201-209.

Needleman P, Turk J, Jakschik BA, Morrison AR \& Lefkowith JB 1986 Arachidonic acid metabolism. Annual Review of Biochemistry 55 69-102.

Nishikawa T, Omura M, Noda M \& Yoshida S 1994 Possible involvement of lipoxygenase metabolites of arachidonic acid in the regulation of pregnenolone synthesis in bovine adrenocortical mitochondria. Journal of Biochemistry 116 833-837.

Powell WS 1982 Rapid extraction of arachidonic acid metabolites from biological samples using octadecylsilyl silica. Methods in Enzymology $\mathbf{8 6}$ 467-477.
Rao RM, Jo Y, Leers-Sucheta S, Bose HS, Miller WL, Azhar S \& Stocco DM 2003 Differential regulation of steroid hormone biosynthesis in R2C and MA-10 Leydig tumor cells: role of SR-B1-mediated selective cholesteryl ester transport. Biology of Reproduction 68 114-121.

Reinhart AJ, Williams SC \& Stocco DM 1999 Transcriptional regulation of the StAR gene. Molecular and Cellular Endocrinology 151 161-169.

Resko JA, Norman RL, Niswender GD \& Spies HG 1974 The relationship between progestins and gonadotropins during the late luteal phase of the menstrual cycle in rhesus monkeys. Endocrinology 94 128-135.

Ronco AM, Moraga PF \& Llanos MN 2002 Arachidonic acid release from rat Leydig cells: the involvement of $\mathrm{G}$ protein, phospholipase $\mathrm{A} 2$ and regulation of cAMP production. Journal of Endocrinology 172 95-104.

Simpson ER \& Boyd GS 1966 The cholesterol side-chain cleavage system of the adrenal cortex: a mixed-function oxidase. Biochemical and Biophysical Research Communications 24 10-17.

Simpson ER \& Boyd GS 1967 The cholesterol side-chain cleavage system of bovine adrenal cortex. European Journal of Biochemistry 2 275-285.

Stocco DM 2001 Tracking the role of a star in the sky of the new millennium. Molecular Endocrinology 15 1245-1254.

Stocco DM \& Clark BJ 1996 Regulation of the acute production of steroids in steroidogenic cells. Endocrine Reviews 17 221-244.

Townson DH, Wang XJ, Keyes PL, Kostyo JL \& Stocco DM 1996 Expression of the steroidogenic acute regulatory protein in the corpus luteum of the rabbit: dependence upon the luteotropic hormone, estradiol-17 beta. Biology of Reproduction 55 868-874.

Wang XJ \& Stocco DM 1999 Cyclic AMP and arachidonic acid: a tale of two pathways. Molecular and Cellular Endocrinology 158 7-12.

Wang XJ, Liu Z, Eimerl S, Timberg R, Weiss AM, Orly J \& Stocco DM 1998 Effect of truncated forms of the steroidogenic acute regulatory protein on intramitochondrial cholesterol transfer. Endocrinology 139 3903-3912.

Wang XJ, Walsh LP \& Stocco DM 1999 The role of arachidonic acid on LH-stimulated steroidogenesis and steroidogenic acute regulatory protein accumulation in MA-10 mouse Leydig tumor cells. Endocrine 10 7-12.

Wang XJ, Walsh LP, Reinhart AJ \& Stocco DM 2000 The role of arachidonic acid in steroidogenesis and steroidogenic acute regulatory (StAR) gene and protein expression. Journal of Biological Chemistry 275 20204-20209.

Wang XJ, Dyson MT, Mondillo C, Patrignani Z, Pignataro O \& Stocco DM 2002 Interaction between arachidonic acid and cAMP signaling pathways enhances steroidogenesis and StAR gene expression in MA-10 Leydig tumor cells. Molecular and Cellular Endocrinology 188 55-63.

Wang XJ, Dyson MT, Jo Y \& Stocco DM 2003a Inhibition of cyclooxygenase- 2 activity enhances steroidogenesis and steroidogenic acute regulatory gene expression in MA-10 mouse Leydig cells. Endocrinology 144 $3368-3375$

Wang XJ, Dyson MT, Jo Y, Eubank DW \& Stocco DM $2003 b$ Involvement of 5-lipoxygenase metabolites of arachidonic acid in cyclic AMP-stimulated steroidogenesis and steroidogenic acute regulatory protein gene expression. Journal of Steroid Biochemistry and Molecular Biology 85 159-166.

Wang XJ, Shen CL, Dyson MT, Eimerl S, Orly J, Hutson JC \& Stocco DM 2005 Cyclooxygenase-2 regulation of the age-related decline in testosterone biosynthesis. Endocrinology 146 4202-4208.

Zosmer A, Elder MG \& Sullivan MH 1990 Production of intracellular arachidonic acid metabolites by human granulosa cells. Prostaglandins, Leukotrienes, and Essential Fatty Acids 41 265-267.

Zosmer A, Elder MG \& Sullivan MH 2002 The production of progesterone and 5,6-epoxyeicosatrienoic acid by human granulosa cells. Journal of Steroid Biochemistry and Molecular Biology 81 369-376.

Received 24 April 2006

Received in final form 19 June 2006

Accepted 23 June 2006 